\title{
PARENTAL INFLUENCE ON ADOLESCENT GIRLS‘ EATING BEHAVIOR
}

\author{
Elena N. Pencheva ${ }^{1}$, Darina N. Hristova ${ }^{2}$ \\ 1) Department of Hygiene and Epidemiology, Faculty of Public Health, Medi- \\ cal University - Varna, Bulgaria. \\ 2) Department of Preclinical and Clinical Sciences, Faculty of Pharmacy, Medi- \\ cal University - Varna, Bulgaria.
}

\begin{abstract}
:
Introduction: The balanced nutrition of children defines their optimal growth and development. The family plays a key role in the formation of healthy eating habits in childhood. In the last decades an increasing prevalence of alternative diets, significantly differing from healthy nutrition is observed among children and adolescents. This type of dieting creates short and long term health risks.

Aim: The aim of this article is to represent the role of the family in the formation of adolescent girls' eating behavior.

Materials and methods: A literature review of 14 sources has been made.

Results: The literature review demonstrates the powerful parental influence on the formation of their descendants ' eating behavior. Findings indicate that the parental encouragement of dieting to lose weight is related to the earlier shift towards alternative diets among their daughters. There is accumulating evidence for the detrimental effect of controlling feeding practices on children's ability to self-regulate energy intake. Results suggest that the critical comments in the family regarding weight and body shape are associated with body dissatisfaction, unhealthy and extreme weight control behaviors. A lower percentage of alternative dieting and disordered eating behaviors is reported in a family with more frequent family meals and discussions about weight.

Conclusions: Parents play the role of educators in the life of children modeling their food cognitions and preferences. Appropriate education of parents would be useful to establish healthy family meal patterns and to reduce the risk of developing eating disorders.
\end{abstract}

Keywords: adolescents, eating behavior, parents

\section{BACKGROUND:}

The balanced nutrition of children defines their optimal growth and development. At the same time, it is an important factor for the prevention of chronic non-communicable diseases when healthy eating habits are needed to be formed during childhood. The family plays a key role in this process.

In the last decades an increasing prevalence of al- ternative diets, significantly differing from healthy nutrition is observed among children and adolescents, most commonly due to a desire to lose weight. This type of dieting creates short and long term health risks. Furthermore, alternative diets are associated with an increased possibility of developing eating disorders (ED).

The current review summarizes the role of the family in the formation of adolescent girls " eating behavior.We focus our study on the group of adolescent girls because of the fact that they represent a susceptible group with higher risk to alternative dieting with unhealthy and extreme methods. The supportive family environment is crucial for the prevention of ED.

\section{REVIEW RESULTS:}

Research on the population's eating behavior in Bulgaria reveals an increased risk for the development of ED among people aged from 10 to 18 years in both female $(30.5 \%)$ and male $(27 \%)$ individuals, especially aged from 14 to 18 years (35.3\%) [1]. An increased risk is observed in both groups of overweight $(31 \%)$ and normal $(25.2 \%)$ weight children, classified by BMI, as well as in the group with underweight girls (25\%) aged from 14 to 18 years. An updated version of The Eating Attitudes Test (EAT-26), recommended by the American Psychiatric Association, is applied as a screening instrument. A self-induced vomiting, as well as a laxative and diuretics use, are reported by 1.2$6.2 \%$ of all investigated children. A significant part of them wants to be slimmer, even those with normal weight.

Results show that eating behavior of the Bulgarian children can be defined as risky. Obviously, prevention measures are necessary to be taken at different levels. An important step towards the restriction of unhealthy eating patterns would be better education of the parents regarding healthy nutrition and weight-related problems.

Majority of researches demonstrate the powerful parental influence on the formation of their descendants " eating behavior. One of them, conducted in Pennsylvania, investigated the association between maternal and paternal encouragement to diet and their daughters' self-reported "early dieting" (prior to age 11 years) and adolescent dieting (between 11 and 15 years), and how parental encouragement to diet is related to changes in daughters' BMI 
percentiles. Participants in this study were 174 girls and their parents, assessed when daughters were 9-, 11-, 13-, and 15 years. Findings indicate that parental encouragement of dieting to lose weight is related to the earlier shift towards alternative diets among their daughters [2]. Girls who are encouraged to diet by their mothers or fathers are twice more likely to be on a diet by 11 years of age. Girls who are encouraged to diet by both parents are 8 times more likely to report early dieting than girls who are not. Girls who dieted and had parental encouragement to do so had increased in BMI percentile from 9 to 15 years. Other analyses of the same collected data have shown that girls whose mothers are dieting are significantly more likely to be on a diet before the age of 11 years, than those whose mothers are not, independently from their weight status. Near $70 \%$ of overweight girls at the age of 9 years are encouraged to diet [3]. The levels of maternal and paternal encouragement are higher among overweight adolescent girls [4].

The similar research investigated the influences of mothers' dieting behaviors and eating habits on their junior high school daughters. The subjects are classified into three groups. The first group of adolescent girls followed alternative diets aiming at losing weight fast with unhealthy methods. The second group includes subjects who stuck to a moderate diet with structured patterns in order to achieve slow, gradual and steady weight loss. The third group of girls did not diet. Data analysis shows strong relationship between the dieting behavior of the mothers and those of their daughters. Mothers whose daughters used unhealthy methods to lose weight had significantly higher scores for the questions concerning dieting behavior and lower scores for questions concerning eating consciousness. The number of cases of conversation about diet is higher in the first group compared to the non-diet group [5]. Findings reveal that parental encouragement to diet may be counterproductive and that parents need alternative approaches to promote healthy patterns of nutrition among young girls.

According to the literature in this field, there is accumulating evidence for the detrimental effect of controlling feeding practices on children's ability to self-regulate energy intake. A study, involving 2793 adolescents and their parents in Minnesota, examined food-related parenting practices and associations with adolescent weight status. Two types of controlling feeding practices, including pressure-to-eat and restriction, are assessed by answering a questionnaire. Results show that the parents of overweight and obese adolescents imposed more often feeding restrictions than those of the nonoverweight adolescents. Fathers were inclined to apply more pressure-toeat practices than mothers. The race and socioeconomic status do not influence significantly the correlation between the controlling feeding practices and the adolescents weight status [6].

Another group of investigators found that the maternal emotional responses to children negative emotions influence the frequency of maternal binge eating (BE) and child feeding practices. Maternal BE predicted use of more nonresponsive feeding practices like emotion regulation, restrictions, pressure-to-eat and food as a reward. The last one contributes to increased child eating, weight gain and higher child BMI percentile [7, 8].

The social environment at school age influences susceptible self-assessment and emotional well-being. Adolescent girls from Minneapolis participated in research examining the relationship between family weight talk and weight-teasing and girls ' weight-related problems [9]. Results suggest that the critical comments in the family regarding weight and body shape are associated with body dissatisfaction, unhealthy and extreme weight control behaviors, and binge eating with loss of control in the girls. Furthermore, the critical comments may be a trigger factor for alternative dieting and may contribute to eating disorders. A high percentage of girls $(45 \%)$ reported that their mothers encouraged them to diet and $58 \%$ reported weightteasing by family members. Near $40 \%$ of the participants indicate that their fathers also diet. A lower percentage of alternative dieting and disordered eating behaviors is reported in a family with more frequent family meals and discussions about weight.

Children's food intake at school age is strongly dependent on parental eating behavior. Parents are important socialization agents who play the role of health promoters, role models, and educators in the lives of their children $[10,11,12]$. A study was designed to examine family factors influencing the development of children food preferences. Results indicate a strong correlation with the different parental practices including active guidance/education, restrictive guidance/rule-making, availability, accessibility, modeling, the pressure to eat, rewarding food consumption, rewarding with verbal praise, and using food as a reward. Findings suggest that active guidance/education might be more effective for encouraging healthy foods consumption (fruits and vegetables) while for unhealthy foods (sugar-sweetened beverages and snack consumption) restrictive guidance/rule-making might be more effective as well as controlling the availability. For children at the age of 7 years and older, restrictive guidance/rule-making could be more effective in preventing unhealthy eating habits while for younger children rewarding with verbal praise can be more appropriate in promoting healthy eating [12]. A recent study revealed that having health-oriented food rules at home contributes to healthier snack choices among adolescents [13].

Research in the past decade has established a direct association between family meal frequency and healthy dietary intake of adolescents. The family meal and social interactions during the meal are related to children weight status, the development of children eating patterns and socialization. A systematic research review of observational approaches, including 13 articles is used to evaluate mother-child mealtime interactions during preschool years. It is found that the parental discouragements to eat and negative statements about food were associated with higher child weight status [14]. 


\section{CONCLUSIONS:}

The findings suggest that parents should be educated and empowered through anticipatory guidance to encourage moderation rather than overconsumption and emphasize on healthier food choices rather than restrictive eating patterns. Children are "imitators," they need to emulate their mentor (parent) adopting eating behaviors.

\section{Abbreviations: \\ ED - eating disorders \\ BE - binge eating}

\section{REFERENCES:}

1. Petrova S, Zyumbyuleva J, Duleva V, Rangelova L, Bojilova D. Nutritional behavior of the population in Bulgaria aged 10 to 40 years. [in Bulgarian] 2014. [nternet]

2. Balantekin KN, Savage JS, Marini ME, Birch LL. Parental encouragement of dieting promotes daughters' early dieting. Appetite. 2014 Sep;80:190-6. [PubMed] [Crossref].

3. Coffman DL, Balantekin KN, Savage JS. Using Propensity Score Methods To Assess Causal Effects of Mothers' Dieting Behavior on Daughters' Early Dieting Behavior. Child Obes. 2016 Oct;12(5):334-40. [PubMed] [Crossref]

4. Fulkerson JA, McGuire MT, Neumark-Sztainer D, Story M, French SA, Perry CL. Weight-related attitudes and behaviors of adolescent boys and girls who are encouraged to diet by their mothers. Int J Obes Relat Metab Disord. 2002 Dec;26(12):1579-87. [PubMed] [CrossRef]

5. Hirokane K, Tokumura M, Nanri S, Kimura K, Saito I. Influences of mothers' dieting behaviors on their junior high school daughters. Eat Weight Disord. 2005 Sep;10(3):162-7. [PubMed]
6. Loth KA, MacLehose RF, Fulkerson JA, Crow S, NeumarkSztainer D. Food-related parenting practices and adolescent weight status: a population-based study. Pediatrics. 2013 May;131(5):e1443-50. [PubMed] [Crossref]

7. Saltzman JA, Pineros-Leano M, Liechty JM, Bost KK, Fiese BH, STRONG Kids Team. Eating, feeding, and feeling: emotional responsiveness mediates longitudinal associations between maternal binge eating, feeding practices, and child weight. Int J Behav Nutr Phys Act. 2016 Aug 2;13:89. [PubMed] [Crossref].

8. Saltzman JA, Liechty JM, Bost KK, Fiese BH, STRONG Kids Team. Parent binge eating and restrictive feeding practices: Indirect effects of parent's responses to child's negative emotion. Eat Behav. 2016 Apr;21:150-4. [PubMed] [Crossref]

9. Neumark-Sztainer D, Bauer KW, Friend S, Hannan PJ, Story M, Berge JM. Family weight talk and dieting: how much do they matter for body dissatisfaction and disordered eating behaviors in adolescent girls? $J$ Adolesc Health. 2010 Sep;47(3):270-6. [PubMed] [Crossref]
10. Yee AZ, Lwin MO, Ho SS. The influence of parental practices on child promotive and preventive food consumption behaviors: a systematic review and meta-analysis. Int J Behav Nutr Phys Act. 2017 Apr 11;14(1):47. [PubMed] [Crossref].

11. Sleddens EF, Kremers SP, Stafleu A, Dagnelie PC, De Vries NK, Thijs C. Food parenting practices and child dietary behavior. Prospective relations and the moderating role of general parenting. Appetite. 2014 Aug;79:4250. [PubMed] [Crossref].

12. Ventura AK, Worobey J.Early influences on the development of food preferences. Curr Biol. 2013 May 6;23(9):R401-8. [PubMed] [Crossref]

13. Wang J, Fielding-Singh P. How Food Rules at Home Influence Independent Adolescent Food Choices. J Adolesc Health. 2018 May 15. pii: S1054-139X(18)30133-2. [PubMed] [Crossref]

14. Bergmeier H, Skouteris H, Hetherington M. Systematic research review of observational approaches used to evaluate mother-child mealtime interactions during preschool years. Am J Clin Nutr. 2015 Jan;101(1):7-15. [PubMed] [Crossref]

Please cite this article as: Pencheva EN, Hristova DN. Parental influence on adolescent girls' eating behavior. $J$ of IMAB. 2018 Oct-Dec;24(4):2295-2297. DOI: https://doi.org/10.5272/jimab.2018244.2295

Address for correspondence:

Elena Nikolaeva Pencheva

Department of Hygiene and Epidemiology, Faculty of Public Health, Medical University of Varna

55, Marin Drinov Str., 9000, Varna, Bulgaria.

E-mail: eli_dimitrova9@abv.bg 